\title{
Microbiota, Fiber, and NAFLD: Is There Any Connection?
}

\author{
Alejandra Pérez-Montes de Oca ${ }^{\dagger} \mathbb{C}$, María Teresa Julián ${ }^{\dagger}$, Analía Ramos, Manel Puig-Domingo ${ }^{\ddagger}$ \\ and Nuria Alonso *, $\ddagger$ \\ Endocrine and Nutrition Service, Germans Trias i Pujol Hospital and Research Institute, \\ Universitat Autònoma de Barcelona, 08916 Badalona, Spain; alec148@gmail.com (A.P.-M.d.O.); \\ mtjulian.germanstrias@gencat.cat (M.T.J.); analiaemilceramos@gmail.com (A.R.); mpuigd@igtp.cat (M.P.-D.) \\ * Correspondence: nurialonsopedrol@gmail.com; Tel.: +934-978-800 \\ + Both authors contributed equally to this work. \\ $\ddagger$ Both authors contributed equally to this work.
}

Received: 7 September 2020; Accepted: 9 October 2020; Published: 12 October 2020

\begin{abstract}
Gut microbiota can contribute to the development and progression of non-alcoholic fatty liver disease (NAFLD). In fact, some specific changes of gut microbiota are observed in patients in what is called dysbiota. There has been a lot of investigation by using a variety of interventions, including diet, showing the possibility to modify components of gastrointestinal dysbiota towards healthy and multivariate microbiota to restore physiologic status. One of the main focuses has been dietary fiber $(\mathrm{DF})$, in which most of its variants are prebiotics. The highest effective treatment for NAFLD is, so far, weight loss achieved by caloric restriction. DF supplementation with oligofructose facilitates weight loss, enhances the production of beneficial metabolites, decreases some pathogenic bacteria population by increasing Bifidobacteria, and has effects on intestinal barrier permeability. DF use has been associated with improvement in diverse metabolic diseases, including NAFLD, by modifying gut microbiota. Additionally, it has been shown that a higher insoluble fiber consumption ( $\geq 7.5 \mathrm{~g} /$ day) revealed improvements in 3 different scores of liver fibrosis. Further research is needed, but given the evidence available, it is reasonable to prescribe its consumption in early stages of NAFLD in order to prevent disease progression.
\end{abstract}

Keywords: NAFLD; NASH; microbiota; fiber; prebiotics; diet

\section{Introduction}

Non-alcoholic fatty liver disease (NAFLD) is rapidly becoming one of the most important causes of liver disease and its global prevalence is currently estimated at $24 \%$ [1]. The incidence of NAFLD has grown worldwide, in parallel to the obesity pandemic. NAFLD is strongly associated with obesity and other metabolic disorders such as type 2 diabetes (T2D) and dyslipidemia [2]. Along with these comorbidities, the most common cause of death for these patients is cardiovascular disease (CVD) [3]. They also have a high risk of liver-related morbidity and mortality [1]. Around 20-30\% of patients with NAFLD will develop non-alcoholic steatohepatitis (NASH) that can lead to progressive liver damage, cirrhosis, and hepatocellular carcinoma [4]. The pathogenesis of NAFLD has not been fully elucidated. The most widely supported theory implicates insulin resistance as the key mechanism with an alteration in hepatic lipid homeostasis, mitochondrial dysfunction, and lipotoxicity [5]. It is well known that not only the liver plays a role, but also the pancreas, the stomach, the adipose tissue, the muscle, and more interesting the intestines and their microbiota [4].

NAFLD diagnosis requires demonstration of hepatic steatosis by imaging or biopsy, exclusion of significant alcohol consumption and other secondary causes, but liver biopsy remains as the gold 
standard for histological evaluation [6]. Currently, effective treatment for NASH is limited and drugs potentially useful are not yet completely established. Lifestyle interventions are recommended and mandatory by the American and European guidelines [3,6], while studies have shown that diet is one of the most important and promising treatments leading to the prevention and reversal of fibrosis, even in advanced stages $[7,8]$. What diet and whether the quantity is better than quality remains to be the focus of study. Evidence suggests that lowering caloric intake by at least $30 \%$ or by approximately 750-1000 Kcal/day results in an improvement in insulin resistance and hepatic steatosis [9]; and 7-10\% of weight loss can lead to steatosis resolution and more importantly regression of fibrosis [6-8]. Even though studies mention that a hypocaloric diet is the most important component beyond quality or composition, a moderate restriction of carbohydrates and emphasis on high fiber and monounsaturated fatty acids seem to be a reasonable option [5]. Fiber consumption may play an important role in NAFLD, not only as a nutritional plan component that can help to lose weight but also as part of its pathogenesis involving intestine microbiota.

\section{Intestinal Microbiota}

The gastrointestinal tract (GIT) microbiota is one of the most densely populated microbial communities on earth $[10,11]$. It includes bacteria, fungi, viruses, and archaea, though the first ones are the overwhelming majority [12]. Its distribution is heterogeneous, being the large intestine the predominant location and the main site where the fermentation process occurs. The intestinal microbiota has been described as a "virtual organ" due to the different functions it performs. These include pathogenic defense, energy homeostasis, immune development, and an essential role in physiologic digestive function [12,13].

The gut microbiota that deviates from the 'healthy' status in terms of diversity and functionality is called dysbiotic. It has been associated with a lot of pathologies including inflammatory bowel diseases, obesity and T2D [14,15]. Alterations in gastrointestinal microbiota lead to intestinal barrier dysfunction through several mechanisms including a "leaky gut". This happens when proteins that are responsible for tight junctions such as claudins, zonulin, and occludin, are compromised by changing its distribution and allowing a higher intestinal permeability to bacterial components [16-18]. These phenomena promote metabolic endotoxemia and contribute to the development of a chronic low-grade inflammatory state in both the adipose tissue and the liver $[19,20]$. Moreover, the integrity of the intestinal barrier could be disrupted by microbial metabolites such as ethanol, that has an increased production in a dysbiotic gut ecosystem, and other volatile organic compounds, leading to further greater liver injury in the setting of amplified hepatic fat accumulation [16]. Therefore, gut-liver axis derangement such as gastrointestinal dysbiosis and production of inflammatory molecules, among others lipopolysaccharide, might modulate the progression of NAFLD by promoting bacteria/bacterial product translocation into portal circulation and activation of inflammation via toll-like receptors signaling in hepatocytes [4,21].

The intestinal microbiota is different from host to host. Recent studies have identified gut microbes associated with potential beneficial outcomes (e.g., Bifidobacterium, Lactobacillus, Faecalibacterium, Roseburia, Ruminococcus, Bacteroides sp.) and potential harmful outcomes (e.g., Clostridium, Enterobacter, Enterococcus sp.). The beneficial outcomes include anti-inflammatory effects in the gut and favorable action in metabolic parameters [13]. Two studies [22,23] comparing NAFLD patients with healthy controls found an increased abundance of the Lactobacillus genus, and a decrease in the family Ruminococcaceae in NAFLD patients. Another study comparing NAFLD, NASH and healthy subjects described a decreased percentage of Bacteroides in NASH patients [24]. Moreover, a study comparing the microbiota composition in children with NASH vs. healthy and obese children found a gradual rise in Proteobacteria [25]. Furthermore, a cross-sectional study comparing the gut microbiome of obese and lean patients with or without NASH found that, in comparison with healthy subjects, lean NASH patients showed abundance of Faecalibacterium, and Ruminococcus sp., while obese NASH patients were enriched with Lactobacillus sp. More important, liver fibrosis $\geq$ F2 was associated with an increase of 
Lactobacillus sp. [26]. Interestingly, a study by Zhu based on the characterization of gut microbiomes in NASH patients found a higher abundance of alcohol-producing bacteria when compared to obese or healthy individuals with normal liver function. Specifically, Escherichia from the Proteobacteria phylum was significantly elevated in NASH patients. This study also described an increased blood alcohol concentration with the same pattern. This result suggests that microbes rich in ethanol-producing (Bacteroides, Bifidobacterium, and Clostridium sp.) may be a risk factor in driving the disease progression from obesity/NAFLD to NASH [27]. This theory is supported by other experimental and human studies where bacteria such as Klebsiella pneumoniae and bacteria from the Lactobacillus genus, both ethanol-producing bacteria, were involved in the pathogenesis of NAFLD [28,29].

To sum up, some diseases can modify gut microbiota, but its shaping is also influenced by many other factors and characteristics such as age, genetics, medications and, more relevant, diet. There has been a lot of investigation about how a variety of interventions, including nutritional plan, can affect and modify components of gut microbiota and have subsequent consequences for health status. One of the main focuses has been dietary fiber (DF) $[10,11,13]$.

\section{Dietary Fiber and Prebiotics}

A variety of definitions of DF have been promulgated by scientific and regulatory agencies worldwide. The EU regulation on the provision of food information to consumers [30] defines fiber as "carbohydrate polymers with three or more monomeric units, which are neither digested nor absorbed in the human small intestine. DF has been categorized as follow: (i) edible carbohydrate polymers naturally occurring in the food as consumed, (ii) edible carbohydrate polymers obtained from food raw material by physical, enzymatic or chemical means and which have a beneficial physiological effect demonstrated by generally accepted scientific evidence, and (iii) edible synthetic carbohydrate polymers which have a beneficial physiological effect demonstrated by generally accepted scientific evidence". DF represents the major non-digestible component in most diets and it exerts a physiological influence throughout the digestive tract from the modulation of digestion processes to acting as a prime substrate for microbial fermentation [12]. Particle size and shape, viscosity, as well as extent/rate of fermentation can significantly affect these different functions in the GIT [11].

There are a lot of classifications of DF. The most common one for human nutrition divides it into two subgroups based on its solubility in water: soluble vs. insoluble [12]. Although the World Health Organization (WHO) in 1998 proposed to no longer use this classification [30], it is useful as a predictor of its water-holding capacity, viscosity and degree of fermentation by GIT bacteria from a physicochemical point of view. Insoluble fibers such as cellulose usually found in bran, legumes, and nuts are generally poorly fermented by intestinal microbiota, but they boost gut transit rate and reduce the amount of time available for colonic bacterial fermentation of undigested foodstuff. On the other side, soluble fibers such as pectin and xyloglucans are highly fermentable and can be located in whole grains (e.g., oats and barley [ $\beta$-glucan]) and fruits (e.g., apples [pectin]). Inulin, resistant maltodextrins, resistant starch, polydextrose and soluble corn fiber are others soluble DF that are readily fermented by gastrointestinal microbiota $[11,12,16]$. This fermentation process is one of the main benefits of DF, modulating intestinal microbiota, affecting its diversity and function and the by-products of the process itself [12]. In addition, the degradation of prebiotics provides short-chain fatty acids that fulfill a protective role for colonocytes helping to maintain the proper structure and function of the intestinal barrier [16].

Interestingly, some DFs are prebiotics. Prebiotics are a group of nutrients that are degraded by gut microbiota. The exact definition has changed over the time and in 2010 it included a focus on its functionality: "a selectively fermented ingredient that results in specific changes in the composition and/or activity of the gastrointestinal microbiota, thus conferring benefits upon host health" [31]. There are many types of prebiotics, the most important ones are fructooligosaccharides (FOS) and galactooligosaccharides (GOS). The majority of them can be classified as DF but not all fibers can be listed as prebiotic. They naturally exist in different dietary food products, including asparagus, garlic, 
onion, Jerusalem artichoke, wheat, honey, banana, tomato, soybean, human and cow's milk, peas, beans, among others $[11,17,31]$. Moreover, nowadays they have been added as ingredients to many common food products such as bread and breakfast cereal [32].

Prebiotics have different well-known favorable outcomes. Production of beneficial metabolites (inulin, oligofructose), augmentation of calcium absorption (inulin, oligofructose, GOS), improvement in allergy risk (FOS/GOS), enhancement of the immune system (oligofructose), effects on gut barrier permeability (oligofructose), and decline in pathogenic bacteria population by expanding Bifidobacteria (inulin, oligofructose, GOS) are some of the most known benefits [17].

Several studies have found a relation between DF and prebiotic intake and a growing variety of health-beneficial bacteria. A high-fiber diet enlarges the abundance of Bifidobacterium and reduces the ratio of Firmicutes/Bacteroidetes in humans and experimental animals [13]. A randomized control trial (RCT) comparing the effects of a high fiber diet vs. calorie restricted diet in the modulation of gut microbiome dysbioses in T2D patients found a higher fecal abundance of several beneficial microbiota such as Roseburia sp., Fecalibacterium sp., and Bacteroides sp. in both groups. On the other hand, the fiber-rich diet group had a decreased of pro-inflammatory bacteria, specifically of Collinsella and Streptococcus sp. [33]. Furthermore, a dietary intervention comparing the effects of a diet enriched with two different types of fiber-arabinoxylan and resistant starch type 2- and a low fiber diet found a greater abundance of Bifidobacterium sp. and lowered microbial diversity in the fiber supplemented group [34]. Moreover, RCTs have proved that in healthy adults the consumption of GOS-1.5 to $10 \mathrm{~g} /$ day- for up to 12 weeks rose the fecal level of Bifidobacterium [11,13]. Other studies have shown that supplementation with GOS, inulin, and oligofructose has resulted in an abundance of Bifidobacterium, Lactobacillus, and Faecalibacterium sp. [13] (Table 1).

Table 1. Potential beneficial gut microbiota changes according to modulations of dietary fiber and/or prebiotics [11,13].

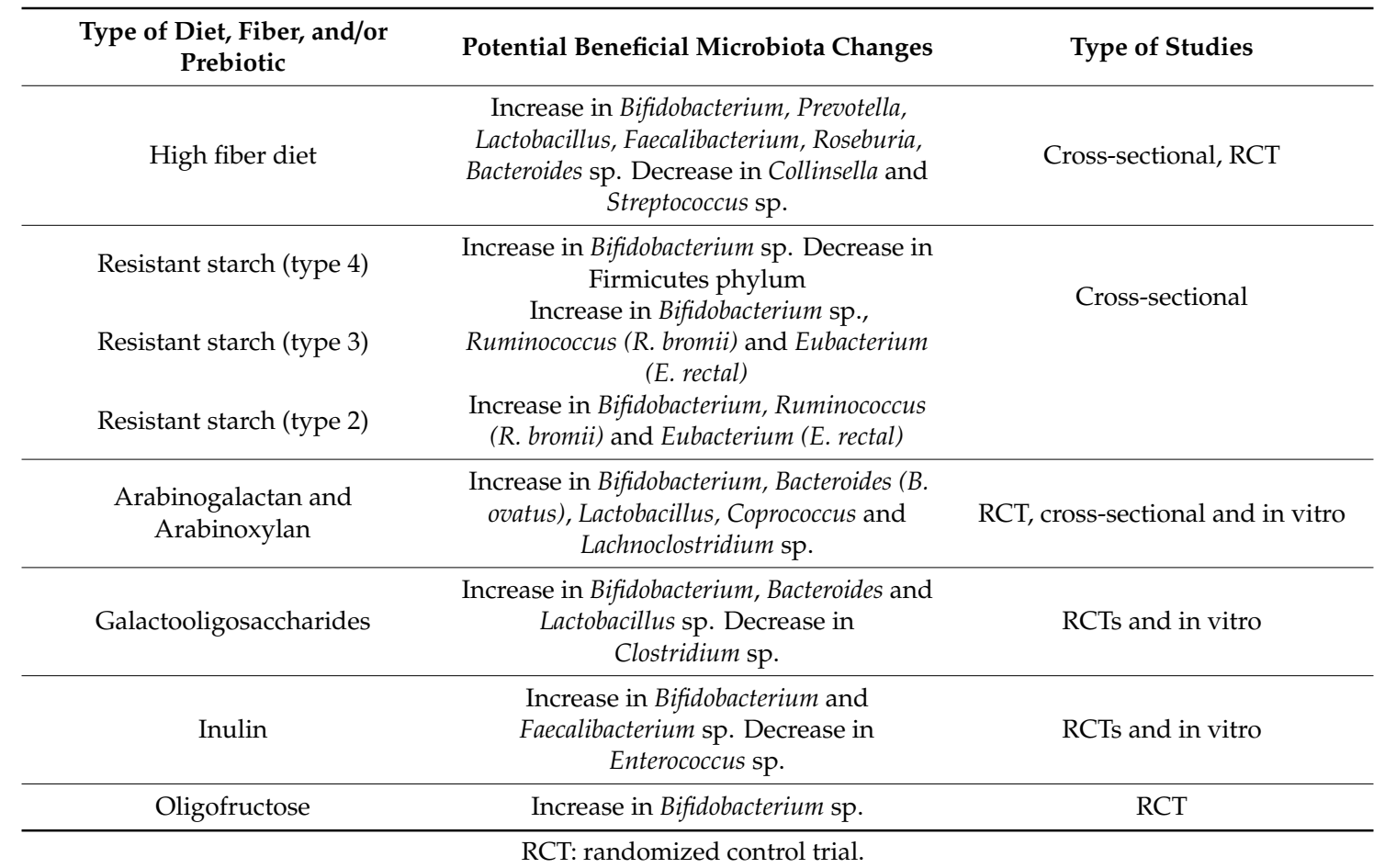




\section{Dietary Fiber and NAFLD}

The health impact of DF, and more recently prebiotics, has been extensively reviewed and accepted worldwide. As mentioned before, they have been linked to different beneficial outcomes [17]. More recently, their use has been associated with the enhancement in diverse metabolic diseases, including NAFLD [35].

As previously described, the most effective treatment for NAFLD is weight loss achieved by caloric restriction [8]. It is known that fiber supplementation reduces the frequency of eating by intensifying satiety through the stimulation of the anorexigenic hormones and suppression of the orexigenic hormone ghrelin. This beneficial effect, in addition to its low energy density, has linked them to weight reduction [36,37]. A randomized control trial (RCT) showed that, independent of other lifestyle changes, fiber supplementation with oligofructose has the potential to promote weight loss and improve glucose regulation in overweight adults compared to placebo [37].

In addition, some prebiotics such as inulin have been associated with reduced body weight or attenuated weight gain $[36,38]$. Beyond weight loss, animal studies suggest that dietary supplementation with prebiotic can have a positive effect on NAFLD by modifying gut microbiota, reducing body fat, and bettering glucose regulation [35]. In humans, an RCT found that increased fiber intake (soluble and insoluble), from $19 \mathrm{~g} /$ day to the $29 \mathrm{~g} /$ day, reduced serum zonulin concentration, decreased liver enzymatic activity, and enhanced hepatic steatosis in patients with NAFLD, possibly by modifying intestinal permeability [16]. In addition, a recent study established a relationship between the degree of liver fibrosis measured by non-invasive assessments and fiber intake. This study found that a higher insoluble fiber consumption ( $\geq 7.5 \mathrm{~g} /$ day) showed improvements in three different scores of liver fibrosis (fatty liver index, hepatic steatosis index, and NAFLD liver fat score), while significant amelioration in hepatic enzymes were observed as a result of fruit fiber consumption ( $\geq 8.8 \mathrm{~g} /$ day) [39]. Furthermore, a 12-week comparison between a commercially available formula diet supplemented with oats fibers versus a comparably restricted nutritional program found that both dietetic interventions were similarly effective regarding weight loss, but the diet supplemented with oats fibers was more efficient regarding the reduction of intrahepatic lipid content detected by hepatorenal index [40]. Other smaller studies and reviews, both in animals and humans, have found a positive association between a specific DF and NAFLD [41-43] (Table 2). High food fibers that are recommended and discouraged in NAFLD are shown in Table 3.

A "high-quality healthy diet" has been proposed to improve hepatic steatosis and metabolic dysfunction in patients with NAFLD, independent of caloric restriction and weight loss [44]. This nutritional program is supported by the idea that lower fiber intake is common in NAFLD [44,45] and is based on moderate to high carbohydrates intake (45-65\% of total daily calories), low to moderate fat intake (below 30-35\% of total calories with a high preference for healthy fat intake-monounsaturated fatty acids and omega-3 polyunsaturated fatty acids), protein intake (15-20\% of total daily calories) and fiber intake increasing the consumption of fruits and vegetables, with more focus on prebiotic fiber. However, a high, fructose-rich diet in the form of added sugar is associated with more intestinal permeability, endotoxemia, higher hepatic TNF- $\alpha$ production, and lipid peroxidation, promoting hepatic steatosis and NAFLD [46].

This diet overlaps with the Mediterranean Diet (MD), which is the most recommended dietary pattern in NAFLD. Currently, clinical guidelines also recommend MD as the nutritional program of choice for NAFLD treatment [6]. In crossover comparisons between MD and a low-fat, high-carbohydrate diet, even without weight loss, MD reduces liver steatosis (assessed by magnetic resonance imaging) and improves insulin sensitivity in an insulin-resistant population with biopsy-proven NAFLD [47]. In different subgroups of the PREDIMED trial [48], an RCT aimed at evaluating the effect of MD on the primary prevention of CVD, supplemented with extra-virgin olive oils or nuts, it was found a reduced prevalence of hepatic steatosis and a delay in the progression of NAFLD [49]. 
Table 2. Published studies evaluating fiber consumption and NAFLD.

\begin{tabular}{|c|c|c|c|}
\hline Author/Year & Type of Study & $\begin{array}{l}\text { Dose, Treatment, and } \\
\text { Follow Up. }\end{array}$ & Results \\
\hline Daubioul et al., 2005 [35] & $\begin{array}{l}\text { Randomized } \\
\text { cross-sectional study }\end{array}$ & $\begin{array}{l}\text { Daily ingestion of } 16 \mathrm{~g} \text { of } \\
\text { oligofructose or } \\
\text { maltodextrin (placebo) in } \\
\text { biopsy-proven NASH } \\
\text { patients for } 8 \text { weeks }\end{array}$ & $\begin{array}{l}\text { Improvement in hepatic } \\
\text { enzymes and insulin } \\
\text { levels in NASH patients } \\
\text { receiving a dietary } \\
\text { supplementation with } \\
\text { dietary fructans }\end{array}$ \\
\hline Rocha et al., 2007 [50] & Cross-sectional study & $\begin{array}{l}\text { Daily ingestion of } 10 \mathrm{~g} \text { of } \\
\text { soluble fibers in patients } \\
\text { with NAFLD during } \\
3 \text { months }\end{array}$ & $\begin{array}{l}\text { After fiber } \\
\text { supplementation, } 75 \% \text { of } \\
\text { the patients presented } \\
\text { normal liver enzymes }\end{array}$ \\
\hline Bozzetto et al., 2012 [51] & $\mathrm{RCT}$ & $\begin{array}{l}\text { Effects of qualitative dietary } \\
\text { changes and exercise } \\
\text { (CHO/fiber vs. MUFA diet) } \\
\text { in obese/overweight patients } \\
\text { with T2D during } 8 \text { weeks }\end{array}$ & $\begin{array}{l}\text { Liver fat content } \\
\text { decreased more in MUFA } \\
\text { diets groups. High-fiber, } \\
\text { low-glycemic index diet } \\
\text { did not influence liver } \\
\text { fat content }\end{array}$ \\
\hline Cantero et al., 2017 [39] & $\mathrm{RCT}$ & $\begin{array}{l}\text { Influence of two energy } \\
\text { restricted diets (AHA diet vs. } \\
\text { RESMENA diet) on } \\
\text { non-invasive markers and } \\
\text { scores of liver damage in } \\
\text { obese patients for } 6 \text { months }\end{array}$ & $\begin{array}{l}\text { In both dietary strategies, } \\
\text { increased insoluble fiber } \\
\text { consumption ( } \geq 7.5 \\
\text { g/day) showed } \\
\text { improvements in } 3 \\
\text { different scores of liver } \\
\text { fibrosis (fatty liver index, } \\
\text { hepatic steatosis index, } \\
\text { and NAFLD liver } \\
\text { fat score) }\end{array}$ \\
\hline Krawczyk et al., 2018 [16] & $\mathrm{RCT}$ & $\begin{array}{l}\text { Increased fiber intake from } \\
19 \mathrm{~g} / \text { day to the } 29 \mathrm{~g} / \text { day } \\
\text { (soluble and insoluble) in } \\
\text { patients with NAFLD for } \\
6 \text { months }\end{array}$ & $\begin{array}{l}\text { Significant } \\
\text { improvements in hepatic } \\
\text { enzymes and of fatty } \\
\text { liver status according to } \\
\text { the Hamaguchi score. } \\
\text { Decreased Zonulin } \\
\text { concentration by nearly } \\
90 \% \text { and correlated with } \\
\text { the amount of dietary } \\
\text { fiber intake as well as the } \\
\text { degree of fatty liver }\end{array}$ \\
\hline $\begin{array}{c}\text { Schweinlin et al., } 2018 \\
\text { [40] }\end{array}$ & $\mathrm{RCT}$ & $\begin{array}{l}\text { Comparison of a } \\
\text { formula-based nutritional } \\
\text { therapy enriched with oats } \\
\text { fiber with a non-formula } \\
\text { isocaloric therapy in obese } \\
\text { patients for } 12 \text { weeks }\end{array}$ & $\begin{array}{l}\text { Diet supplemented with } \\
\text { oats fibers was more } \\
\text { effective regarding the } \\
\text { reduction of intrahepatic } \\
\text { lipid content detected by } \\
\text { hepatorenal index } \\
(1.1 \pm 0.2 \text { vs. } 1.9 \pm 0.3 \text {, } \\
p<0.05)\end{array}$ \\
\hline
\end{tabular}

RCT: randomized control trial, NASH: non-alcoholic steatohepatitis, NAFLD: non-alcoholic fatty liver disease, AHA: American Heart Association, RESMENA: Reduction of Metabolic Syndrome in Navarra, T2D: type 2 diabetes, CHO: carbohydrates, MUFA: monounsaturated fatty acids.

Table 3. High food fibers that are recommended and discouraged in NAFLD.

\begin{tabular}{ccc}
\hline $\begin{array}{c}\text { Less } \\
\text { Recommended }\end{array}$ & \multicolumn{2}{c}{ Most Recommended } \\
\hline Corn & Onion & Tomato \\
Rice & Cereals & Soybean \\
Soft drinks & Garlic & Oat and barley \\
Fruit juices & Leeks & Seed plants \\
Honey & Asparagus & Wheat \\
Syrup & Mushrooms & Jerusalem artichoke \\
\hline
\end{tabular}




\section{Conclusions}

Fiber intake positively influences NAFLD not only by promoting reduced calorie intake, but also by stimulating a healthy gut microbiota, therefore reducing the development of inflammation and liver injury. However, to date, no study has found regression of a more advanced stage of NAFLD, such as fibrosis, in patients with high intake of fiber or prebiotic supplementation. Further research is needed, but given the evidence it is reasonable to indicate its consumption in early stages of NAFLD in order to prevent disease progression.

Funding: This research did not receive any specific grant from any funding agency in the public, commercial or not-for-profit sector.

Conflicts of Interest: The authors declare no conflict of interest.

\section{References}

1. Younossi, Z.; Anstee, Q.M.; Marietti, M.; Hardy, T.; Henry, L.; Eslam, M.; George, J.; Bugianesi, E. Global burden of NAFLD and NASH: Trends, predictions, risk factors and prevention. Nat. Rev. Gastroenterol. Hepatol. 2017, 15, 11-20. [CrossRef]

2. Targher, G.; Bertolini, L.; Rodella, S.; Tessari, R.; Zenari, L.; Lippi, G.; Arcaro, G. Nonalcoholic Fatty Liver Disease Is Independently Associated with an Increased Incidence of Cardiovascular Events in Type 2 Diabetic Patients. Diabetes Care 2007, 30, 2119-2121. [CrossRef]

3. Chalasani, N.; Younossi, Z.; LaVine, J.E.; Charlton, M.; Cusi, K.; Rinella, M.; Harrison, S.A.; Brunt, E.M.; Sanyal, A.J. The diagnosis and management of nonalcoholic fatty liver disease: Practice guidance from the American Association for the Study of Liver Diseases. Hepatology 2018, 67, 328-357. [CrossRef]

4. Kolodziejczyk, A.A.; Zheng, D.; Shibolet, O.; Elinav, E. The role of the microbiome in NAFLD and NASH. EMBO Mol. Med. 2018, 11, e9302. [CrossRef]

5. York, L.W.; Puthalapattu, S.; Wu, G.Y. Nonalcoholic Fatty Liver Disease and Low-Carbohydrate Diets. Annu. Rev. Nutr. 2009, 29, 365-379. [CrossRef]

6. European Association for the Study of the Liver (EASL). EASL-EASD-EASO Clinical Practice Guidelines for the Management of Non-Alcoholic Fatty Liver Disease. Diabetologia 2016, 59, 1121-1140. [CrossRef]

7. Glass, L.M.; Dickson, R.C.; Anderson, J.C.; Suriawinata, A.A.; Putra, J.; Berk, B.S.; Toor, A. Total Body Weight Loss of $\geq 10 \%$ Is Associated with Improved Hepatic Fibrosis in Patients with Nonalcoholic Steatohepatitis. Dig. Dis. Sci. 2014, 60, 1024-1030. [CrossRef]

8. Hannah, W.N.; Harrison, S.A. Effect of Weight Loss, Diet, Exercise, and Bariatric Surgery on Nonalcoholic Fatty Liver Disease. Clin. Liver Dis. 2016, 20, 339-350. [CrossRef]

9. Haufe, S.; Engeli, S.; Kast, P.; Böhnke, J.; Utz, W.; Haas, V.; Hermsdorf, M.; Mähler, A.; Wiesner, S.; Birkenfeld, A.L.; et al. Randomized comparison of reduced fat and reduced carbohydrate hypocaloric diets on intrahepatic fat in overweight and obese human subjects. Hepatology 2011, 53, 1504-1514. [CrossRef]

10. Mills, S.; Stanton, C.; Lane, J.A.; Smith, G.J.; Ross, R.P. Precision Nutrition and the Microbiome, Part I: Current State of the Science. Nutrients 2019, 11, 923. [CrossRef]

11. McRorie, J.W.; Fahey, G.C. A review of gastrointestinal physiology and the mechanisms underlying the health benefits of dietary fiber: Matching an effective fiber with specific patient needs. Clin. Nurs. Stud. 2013, 1, 82-92. [CrossRef]

12. Williams, B.A.; Grant, L.J.; Gidley, M.J.; Mikkelsen, D. Gut Fermentation of Dietary Fibres: Physico-Chemistry of Plant Cell Walls and Implications for Health. Int. J. Mol. Sci. 2017, 18, 2203. [CrossRef] [PubMed]

13. Yang, Q.; Liang, Q.; Balakrishnan, B.; Belobrajdic, D.P.; Feng, Q.-J.; Zhang, W. Role of Dietary Nutrients in the Modulation of Gut Microbiota: A Narrative Review. Nutrients 2020, 12, 381. [CrossRef]

14. Hansen, T.H.; Gøbel, R.J.; Hansen, T.; Pedersen, O. The gut microbiome in cardio-metabolic health. Genome Med. 2015, 7, 33. [CrossRef]

15. Cani, P.D.; Osto, M.; Geurts, L.; Everard, A. Involvement of gut microbiota in the development of low-grade inflammation and type 2 diabetes associated with obesity. Gut Microbes 2012, 3, 279-288. [CrossRef] [PubMed] 
16. Krawczyk, M.; Maciejewska, D.; Ryterska, K.; Czerwińka-Rogowska, M.; Jamioł-Milc, D.; Skonieczna-Żydecka, K.; Milkiewicz, P.; Raszeja-Wyszomirska, J.; Stachowska, E. Gut Permeability Might be Improved by Dietary Fiber in Individuals with Nonalcoholic Fatty Liver Disease (NAFLD) Undergoing Weight Reduction. Nutrients 2018, 10, 1793. [CrossRef] [PubMed]

17. Carlson, J.L.; Erickson, J.M.; Lloyd, B.B.; Slavin, J. Health Effects and Sources of Prebiotic Dietary Fiber. Curr. Dev. Nutr. 2018, 2, nzy005. [CrossRef] [PubMed]

18. Geurts, L.; Neyrinck, A.M.; Delzenne, N.M.; Knauf, C.; Cani, P.D. Gut microbiota controls adipose tissue expansion, gut barrier and glucose metabolism: Novel insights into molecular targets and interventions using prebiotics. Benef. Microbes 2014, 5, 3-17. [CrossRef]

19. Yki-Järvinen, H. Nutritional Modulation of Non-Alcoholic Fatty Liver Disease and Insulin Resistance. Nutrients 2015, 7, 9127-9138. [CrossRef] [PubMed]

20. Frazier, T.H.; DiBaise, J.K.; McClain, C.J. Gut Microbiota, Intestinal Permeability, Obesity-Induced Inflammation, and Liver Injury. J. Parenter. Enter. Nutr. 2011, 35, 14S-20S. [CrossRef]

21. Poeta, M.; Pierri, L.; Vajro, P. Gut-Liver Axis Derangement in Non-Alcoholic Fatty Liver Disease. Children 2017, 4, 66. [CrossRef]

22. Raman, M.; Ahmed, I.; Gillevet, P.M.; Probert, C.S.; Ratcliffe, N.M.; Smith, S.; Greenwood, R.; Sikaroodi, M.; Lam, V.; Crotty, P.; et al. Fecal Microbiome and Volatile Organic Compound Metabolome in Obese Humans with Nonalcoholic Fatty Liver Disease. Clin. Gastroenterol. Hepatol. 2013, 11, 868-875.e3. [CrossRef] [PubMed]

23. Jiang, W.; Wu, N.; Wang, X.; Chi, Y.; Zhang, Y.; Qiu, X.; Hu, Y.; Li, J.; Liu, Y. Dysbiosis gut microbiota associated with inflammation and impaired mucosal immune function in intestine of humans with non-alcoholic fatty liver disease. Sci. Rep. 2015, 5, srep08096. [CrossRef] [PubMed]

24. Mouzaki, M.; Comelli, E.M.; Arendt, B.M.; Bonengel, J.; Fung, S.K.; Fischer, S.E.; McGilvray, I.D.; Allard, J.P. Intestinal microbiota in patients with nonalcoholic fatty liver disease. Hepatology 2013, 58, 120-127. [CrossRef] [PubMed]

25. Hiippala, K.; Jouhten, H.; Ronkainen, A.; Hartikainen, A.; Kainulainen, V.; Jalanka, J.; Satokari, R. The Potential of Gut Commensals in Reinforcing Intestinal Barrier Function and Alleviating Inflammation. Nutrients 2018, 10, 988. [CrossRef]

26. Duarte, S.; Stefano, J.; Miele, L.; Ponziani, F.; Souza-Basqueira, M.; Okada, L.; Costa, F.D.B.; Toda, K.; Mazo, D.; Sabino, E.; et al. Gut microbiome composition in lean patients with NASH is associated with liver damage independent of caloric intake: A prospective pilot study. Nutr. Metab. Cardiovasc. Dis. 2018, 28, 369-384. [CrossRef]

27. Zhu, L.; Baker, S.S.; Gill, C.; Liu, W.; Alkhouri, R.; Baker, R.D.; Gill, S.R. Characterization of gut microbiomes in nonalcoholic steatohepatitis (NASH) patients: A connection between endogenous alcohol and NASH. Hepatology 2013, 57, 601-609. [CrossRef]

28. Yuan, J.; Chen, C.; Cui, J.; Lu, J.; Yan, C.; Wei, X.; Zhao, X.; Li, N.; Li, S.; Xue, G.; et al. Fatty Liver Disease Caused by High-Alcohol-Producing Klebsiella pneumoniae. Cell Metab. 2019, 30, 675-688.e7. [CrossRef]

29. Duarte, S.M.; Stefano, J.T.; Oliveira, C.P. Microbiota and nonalcoholic fatty liver disease/nonalcoholic steatohepatitis (NAFLD/NASH). Ann. Hepatol. 2019, 18, 416-421. [CrossRef]

30. Products, N.E.P.O.D. Scientific Opinion on Dietary Reference Values for carbohydrates and dietary fibre. EFSA J. 2010, 8, 8. [CrossRef]

31. Davani-Davari, D.; Negahdaripour, M.; Karimzadeh, I.; Seifan, M.; Mohkam, M.; Masoumi, S.J.; Berenjian, A.; Ghasemi, Y. Prebiotics: Definition, Types, Sources, Mechanisms, and Clinical Applications. Foods 2019, 8, 92. [CrossRef] [PubMed]

32. Perdomo, C.M.; Frühbeck, G.; Escalada, J. Impact of Nutritional Changes on Nonalcoholic Fatty Liver Disease. Nutrients 2019, 11, 677. [CrossRef] [PubMed]

33. Candela, M.; Biagi, E.; Soverini, M.; Consolandi, C.; Quercia, S.; Severgnini, M.; Peano, C.; Turroni, S.; Rampelli, S.; Pozzilli, P.; et al. Modulation of gut microbiota dysbioses in type 2 diabetic patients by macrobiotic Ma-Pi 2 diet. Br. J. Nutr. 2016, 116, 80-93. [CrossRef] [PubMed]

34. Hald, S.; Schioldan, A.G.; Moore, M.E.; Dige, A.; Lærke, H.N.; Agnholt, J.; Knudsen, K.E.B.; Hermansen, K.; Marco, M.L.; Gregersen, S.; et al. Effects of Arabinoxylan and Resistant Starch on Intestinal Microbiota and Short-Chain Fatty Acids in Subjects with Metabolic Syndrome: A Randomised Crossover Study. PLoS ONE 2016, 11, e0159223. [CrossRef] [PubMed] 
35. Parnell, J.A.; Raman, M.; Rioux, K.P.; Reimer, R.A. The potential role of prebiotic fibre for treatment and management of non-alcoholic fatty liver disease and associated obesity and insulin resistance. Liver Int. 2011, 32, 701-711. [CrossRef]

36. Solah, V.; Kerr, D.A.; Hunt, W.; Johnson, S.; Boushey, C.J.; Delp, E.J.; Meng, X.; Gahler, R.J.; James, A.P.; Mukhtar, S.A.; et al. Effect of Fibre Supplementation on Body Weight and Composition, Frequency of Eating and Dietary Choice in Overweight Individuals. Nutrients 2017, 9, 149. [CrossRef]

37. Parnell, J.A.; Reimer, R.A. Weight loss during oligofructose supplementation is associated with decreased ghrelin and increased peptide YY in overweight and obese adults. Am. J. Clin. Nutr. 2009, 89, 1751-1759. [CrossRef]

38. Ferrarese, R.; Ceresola, E.R.; Preti, A.; Canducci, F. Probiotics, prebiotics and synbiotics for weight loss and metabolic syndrome in the microbiome era. Eur. Rev. Med. Pharm. Sci. 2018, 22, 7588-7605.

39. Cantero, I.; Abete, I.; Monreal, J.I.; Martinez, J.A.; Zulet, M.A. Fruit Fiber Consumption Specifically Improves Liver Health Status in Obese Subjects under Energy Restriction. Nutrients 2017, 9, 667. [CrossRef]

40. Schweinlin, A.; Ulbrich, S.; Stauß, S.; Teutsch, M.; Walle, H.; Basrai, M.; Bischoff, S.C. Vergleich einer kommerziell erhältlichen, Formula-basierten, mit Haferballaststoffen angereicherten Ernährungstherapie mit einer isokalorischen diätetischen Therapie ohne Formula zur Therapie der nicht-alkoholischen Fettlebererkrankung (NAFLD) eine randomisierte, kontrollierte Interventionsstudie. Z. Gastroenterol. 2018, 56, 1247-1256. [CrossRef]

41. Chang, W.-C.; Jia, H.; Aw, W.; Saito, K.; Hasegawa, S.; Kato, H. Beneficial effects of soluble dietary Jerusalem artichoke (Helianthus tuberosus) in the prevention of the onset of type 2 diabetes and non-alcoholic fatty liver disease in high-fructose diet-fed rats. Br. J. Nutr. 2014, 112, 709-717. [CrossRef]

42. Stice, C.P.; Xia, H.; Wang, X.-D. Tomato lycopene prevention of alcoholic fatty liver disease and hepatocellular carcinoma development. Chronic Dis. Transl. Med. 2018, 4, 211-224. [CrossRef]

43. Yamazaki, T.; Li, D.; Ikaga, R. Effective Food Ingredients for Fatty Liver: Soy Protein $\beta$-Conglycinin and Fish Oil. Int. J. Mol. Sci. 2018, 19, 4107. [CrossRef]

44. Eslamparast, T.; Tandon, P.; Raman, M. Dietary Composition Independent of Weight Loss in the Management of Non-Alcoholic Fatty Liver Disease. Nutrients 2017, 9, 800. [CrossRef]

45. Wehmeyer, M.H.; Zyriax, B.-C.; Jagemann, B.; Roth, E.; Windler, E.; Wiesch, J.S.Z.; Lohse, A.W.; Kluwe, J. Nonalcoholic fatty liver disease is associated with excessive calorie intake rather than a distinctive dietary pattern. Medicine 2016, 95, e3887. [CrossRef]

46. Romero-Gómez, M.; Zelber-Sagi, S.; Trenell, M. Treatment of NAFLD with diet, physical activity and exercise. J. Hepatol. 2017, 67, 829-846. [CrossRef]

47. Ryan, M.C.; Itsiopoulos, C.; Thodis, T.; Ward, G.; Trost, N.; Hofferberth, S.; O'Dea, K.; Desmond, P.V.; Johnson, N.A.; Wilson, A.M. The Mediterranean diet improves hepatic steatosis and insulin sensitivity in individuals with non-alcoholic fatty liver disease. J. Hepatol. 2013, 59, 138-143. [CrossRef]

48. Estruch, R.; Ros, E.; Salas-Salvadó, J.; Covas, M.-I.; Corella, D.; Arós, F.; Gómez-Gracia, E.; Ruiz-Gutiérrez, V.; Fiol, M.; Lapetra, J.; et al. Primary Prevention of Cardiovascular Disease with a Mediterranean Diet Supplemented with Extra-Virgin Olive Oil or Nuts. N. Engl. J. Med. 2018, 378, e34. [CrossRef]

49. Pintó, X.; Fanlo-Maresma, M.; Corbella, E.; Corbella, X.; Mitjavila, M.T.; Moreno, J.J.; Casas, R.; Estruch, R.; Corella, D.; Bulló, M.; et al. A Mediterranean Diet Rich in Extra-Virgin Olive Oil Is Associated with a Reduced Prevalence of Nonalcoholic Fatty Liver Disease in Older Individuals at High Cardiovascular Risk. J. Nutr. 2019, 149, 1920-1929. [CrossRef]

50. Rocha, R.; Cotrim, H.P.; Siqueira, A.C.; Floriano, S. Fibras solúveis no tratamento da doença hepática gordurosa não-alcoólica: Estudo piloto. Arq. Gastroenterol. 2007, 44, 350-352. [CrossRef] [PubMed]

51. Bozzetto, L.; Prinster, A.; Annuzzi, G.; Costagliola, L.; Mangione, A.; Vitelli, A.; Mazzarella, R.; Longobardo, M.; Mancini, M.; Vigorito, C.; et al. Liver Fat Is Reduced by an Isoenergetic MUFA Diet in a Controlled Randomized Study in Type 2 Diabetic Patients. Diabetes Care 2012, 35, 1429-1435. [CrossRef] [PubMed]

(C) 2020 by the authors. Licensee MDPI, Basel, Switzerland. This article is an open access article distributed under the terms and conditions of the Creative Commons Attribution (CC BY) license (http://creativecommons.org/licenses/by/4.0/). 